\title{
Sedimentary graphic logs: A template for description and a toolkit for digitalization
}

\author{
Zane Jobe $^{1, *}$, Nick Howes ${ }^{1,2}$, John Martin ${ }^{2}$, Ross Meyer ${ }^{1}$, Danny Coutts ${ }^{3}$, Pengfei Hou ${ }^{1}$, Lisa Stright ${ }^{4}$ and \\ Fabien Laugier ${ }^{5}$ \\ ${ }^{1}$ Colorado School of Mines, Golden, CO, USA \\ ${ }^{2}$ Shell International Exploration and Production, Inc., Houston, TX, USA \\ ${ }^{3}$ University of Calgary, Calgary, AB, CAN \\ ${ }^{4}$ Colorado State University, Fort Collins, CO, USA \\ ${ }^{5}$ Chevron Center Technology Center, Houston, TX, USA
}

\begin{abstract}
Graphic logs are the most common way geologists characterize and communicate the composition and variability of clastic and carbonate sedimentary successions; with a simple drawing, a graphic log imparts complex geological concepts (e.g., Bouma turbidite sequence, shoreface parasequence). The term 'graphic log' originates from a geologist graphically drawing (i.e., 'logging') an outcrop or core with thickness/depth on the y axis, while the $x$ axis usually represents grain size. Graphic logs can be drawn at vastly different scales, from the characterization of every bed in sections 10 s of meters thick to a rough description of lithology over 1000s of meters, making comprehensive, quantitative comparison difficult.

Many geologists carefully hand-draw graphic logs at fine-scale in a field notebook, and then digitally retrace them in drawing software. However, this detailed data (e.g., thickness, grain size) that may have taken days or weeks to collect is often never captured in a machine-readable, tabular format. So, while tens of thousands of meters of graphic logs exist to quantify lithologic heterogeneity and stacking patterns within and between depositional environments, this data is rarely digital and available for analysis. Despite this, geologists have long been attempting to quantify graphic log data to better distinguish stacking patterns, depositional processes, and depositional environments to aid in prediction of stratigraphic architecture and earth-resource distribution.

We present litholog, an open-source software package in Python that stores, plots, and analyzes graphic-log data. We also include software in $\mathbf{R}$ and Matlab that digitize hand-drawn graphic logs into a tabular format readable by litholog. We discuss the diversity of graphic log data, the implementation of graphic log data in a digital, structured, tabular format; finally, we recommend methods and provide a template for standardizing collection of this important type of stratigraphic data. It is our hope that these software packages, combined with advances in 'big data' analytics and machine-learning algorithms, will lead to new discoveries in sedimentary geology.
\end{abstract}

KEYWORDS sedimentary graphic log, stratigraphic column, measured section, lithology, stratigraphy, open-source software, Python, data standardization, digitalization, sedimentary geology

\section{INTRODUCTION}

G raphic logs are the most common way geologists charJ acterize and communicate the composition and variability of clastic sedimentary successions in both outcrops and subsurface cores (Fig. 1). The term 'graphic log' originates from a geologist measuring and drawing (i.e., 'logging') an outcrop succession or interval of core graphically, and graphic logs were popularized by Arnold Bouma (e.g., Bouma, 1962). Synonymous terms include graphic columnar section (Compton, 1985, Johnson, 1992), Bouma log

Copyright (c) 2021 by the SEPM Society for Sedimentary Geology

doi: $10.2110 /$ sedred.2021.3.3

Manuscript submitted: 08/09/2021

Manuscript accepted: 10/08/2021

*Corresponding author: zanejobe@mines.edu
(Leeder, 1982), measured stratigraphic section (e.g., Jobe et al., 2010), and stratigraphic column (or strat column; Smith, 1815, Daniels et al., 2019).

Graphic logs generally consist of a series of hand-drawn lithologic intervals that can be drawn at many different scales (Fig. 1), from the detailed characterization of mm-thick depositional units in a single thin-section (e.g., Boulesteix et al., 2019) to every bed in a 10-m-thick outcrop or core succession (e.g., Pierce et al., 2018) to a simplistic description of lithology over 1000s of meters (e.g., Thompson et al., 2015). As such, they have been used to communicate detailed sedimentological processes (e.g., Bouma, 1962, Allen, 1970, Jobe et al., 2012, Pierce et al., 2018, Boulesteix et al., 2019, Hubbard et al., 2020), the stratigraphic evo- 
lution of sediment routing systems (e.g., Graham et al., 1986, Bernhardt et al., 2011, Farrell et al., 2013, Englert et al., 2018, Malkowski et al., 2018, Pattison, 2019b), as well as the fill of entire basins (e.g., Graham et al., 1986, Thompson et al., 2015). The popularization of the graphic log allowed for a simple drawing to impart complex geological concepts; the Bouma and Lowe turbidite sequences (Bouma, 1962, Walker, 1965, Lowe, 1982), the shoreface parasequence (Van Wagoner et al., 1988, Pattison, 2019a,b), and the fluvial point bar (Allen, 1970, Jackson, 1976, Bridge and Tye, 2000, Durkin et al., 2015, 2018) are three examples that use graphic logs to demonstrate process-based vertical facies models for clastic depositional environments. Graphic logs have been particularly useful for analyzing turbidite depositional environments, as it allows the characterization and quantification of the thickness and grain size of each turbidity-current event, or 'event-bed' (e.g., Sadler, 1982, Sylvester, 2007, Fryer and Jobe, 2019).

Geologists have used graphic log data quantitatively at the sedimentary structure scale (Sumner et al., 2012, Rossi et al., 2017), bed scale (Sadler, 1982, Murray et al., 1996, Chen and Hiscott, 1999, Talling, 2001, Sylvester, 2007, Fryer and Jobe, 2019) and lithofacies scale (Miall, 1973, Mutti and Ricci Lucchi, 1978, Walker, 1978, Mutti and Normark, 1987, Bridge and Tye, 2000, Jobe et al., 2010, Burgess, 2016a,b, Malkowski et al., 2018, Reynolds, 2019) in order to better distinguish depositional processes, environments, and stacking patterns. In addition, graphic log data have been utilized to corroborate (or refute) the qualitative observation of cyclic stacking patterns of lithofacies through statistical (e.g., Markov-chains) analysis (Miall, 1973, Murray et al., 1996, Kane and Pontén, 2012, Sumner et al., 2012, Burgess, 2016a,b, Hou et al., 2021). Establishing these stacking-pattern relationships in beds, grain size, and lithofacies is important for subsurface predictions of stratigraphic architecture, natural-resource distribution, and paleoclimate archives (Willis and White, 2000, Falivene et al., 2006, Hessler and Fildani, 2019). Recently, research has focused on the finer scale, where detailed, bed-scale graphic-log data has been digitized and used to distinguish submarine depositional environments and subenvironments (e.g., Hansen et al., 2017, Malkowski et al., 2018, Tőkés and Patacci, 2018, Fryer and Jobe, 2019) as well as document grain size variations in riverine and shallowmarine settings (Reynolds, 2019). While these aggregate statistics retrieved from graphic logs are incredibly valuable, they are often difficult to produce for a large number of stratigraphic sections covering either thick intervals or large spatial areas due to (1) the painstaking analog nature of data collection, and (2) a lack of software to digitize the logs. So, while existing workflows exist to digitize logs have been sufficient (but time-inefficient) for limited quantitative analysis (as discussed above), solutions to digitize, store, and analyze digital graphic-log data are needed that can scale to large, diverse datasets.

This paper presents litholog, a Python package that defines a numerical, tabular format (i.e., schema) for graphic- log data and allows for plotting and quantitative analysis. As part of the litholog release, we also include software in MATLAB and $\mathbf{R}$ to digitize hand-drawn graphic logs into a tabular format readable by litholog. We also discuss important considerations regarding collection of graphic log data and potential ways to standardize the collection of this important type of data that will allow an easier transition from the field notebook to the computer when these data are not collected in a digital format (e.g., with an iPad). We hope that these software packages and recommendations about consistent data collection, combined with advances in machine-learning algorithms, will lead to new discoveries in sedimentary geology.

\section{CHALLENGES OF GRAPHIC LOG DATA}

Although graphic logs are a key tool for sedimentologists and stratigraphers to communicate the nature of the sedimentary record, there is no standardized format for graphic logs (digital or otherwise), although there have been several attempts (Boyles et al., 1986, Johnson, 1992, Farrell et al., 2013). This means that graphic logs are a diverse type of geologic data that varies from author to author, and field area to field area. A typical graphic log generally presents thickness/depth on the $y$ axis, while the $x$ axis (which can increase to the right or to the left) can represent modal grain size, maximum grain size, an outcrop weathering profile/outcrop texture, or sometimes a combination of these parameters. Most geologists draw graphic logs as one column (e.g., Fig. 1A, B), but double-column (Fig. 1C) and multi-column variants are also used that separate lithology, grain size, sedimentary structures, etc. (also see Selley, 1985, Boyles et al., 1986). Because sedimentary geologists focus on different spatial scales (Fig. 1), graphic logs vary from being drawn at the mm-scale (e.g., Boulesteix et al., 2019), the cm-scale (e.g., Pierce et al., 2018), the meter scale (e.g., Jobe et al., 2010), and the formation (100s to 1000s of m) scale (e.g., Thompson et al., 2015). Boyles et al. (1986) even offer an equation to choose a logging scale based on the scale of investigation. Sometimes stacking patterns of beds are drawn true-to-scale (Fig. 1B), and sometimes they are schematized (Fig. 1C). Fine-scale geologic observations (e.g., geometry of lithologic contacts, grain size changes, textures, and sedimentary structures) are handdrawn, sometimes in great detail, and vary in format and style from worker to worker. Thus, it is difficult to ascertain the level of detail in a published graphic log and if it contains the same detail as logs from other authors/areas, making quantitative, comprehensive comparisons difficult.

In addition to lithology and grain size, graphic logs also commonly contain information on primary and secondary structures (e.g., sorting, sedimentary structures, bioturbation, diagenetic features), but again, there is no standardized symbology for these features, although there have been attempts by various authors, government agencies, and companies to create a standard template. Many research groups develop their own symbologies and shorthand, making it difficult to compare/contrast sedimentary 
(A)

Every bed (thin section)
Boulesteix et al., 2019

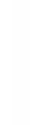
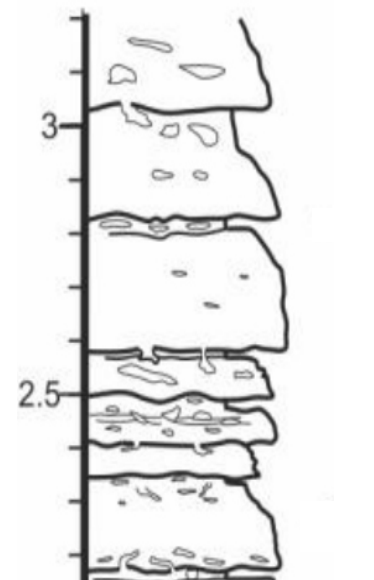

(B)

Every bed (core)

Pierce et al., 2018

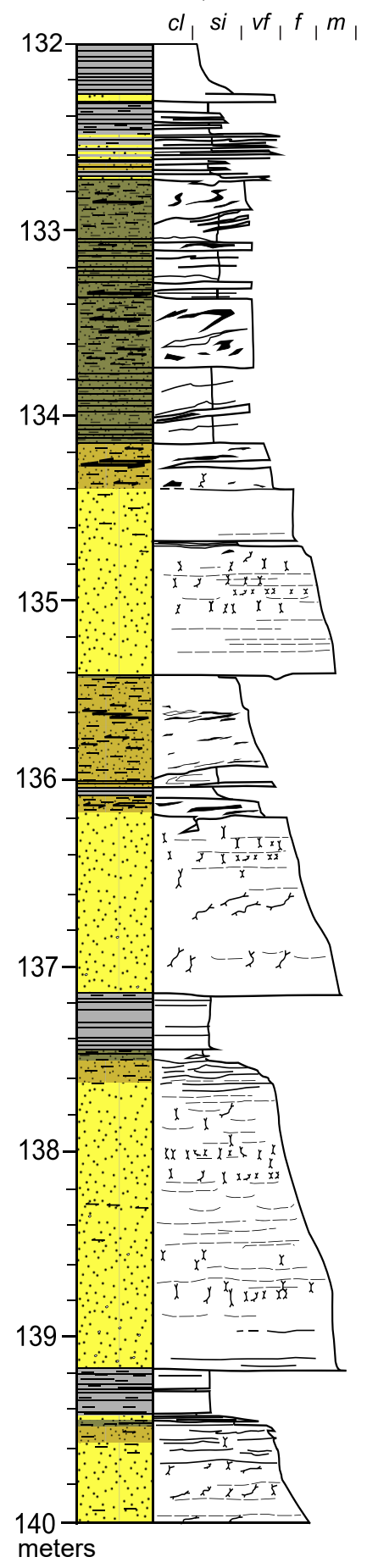

(C)

Detailed, but not every bed Jobe et al., 2010

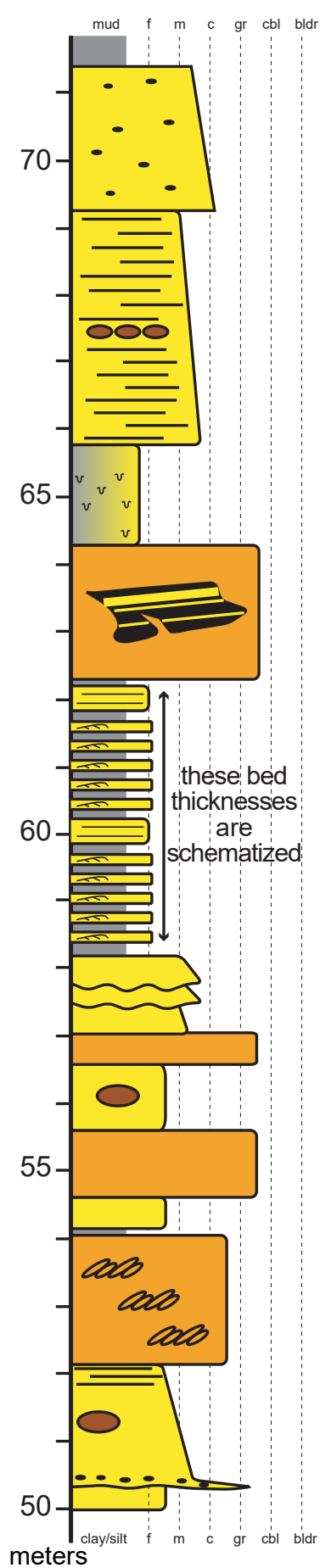

(D)

Formation scale

Thompson et al., 2015

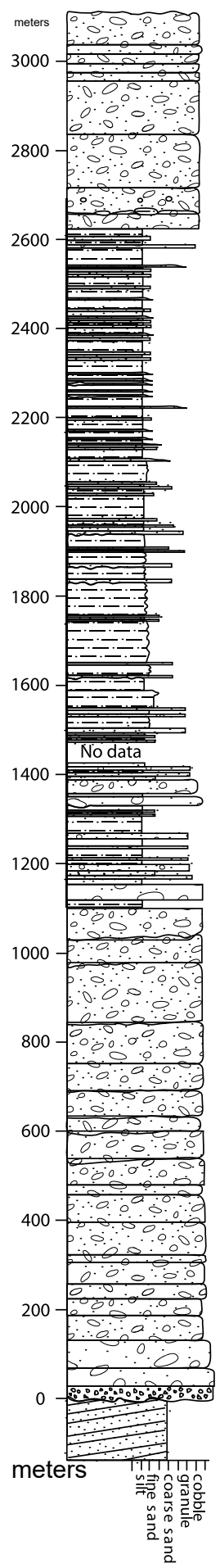

Figure 1: Examples of graphic logs that serve different purposes. (A) Highly detailed graphic log from a thin section, where every $\mathrm{mm}$-scale event-bed and lithologic change is recorded (Boulesteix et al., 2019). (B) Highly detailed graphic log from a core, where every event-bed and lithologic change is recorded (Pierce et al., 2018). (C) Detailed graphic log that captures most bed thicknesses and grain sizes, but schematizes some thin bedded intervals (modified from Jobe et al., 2010). Note also the grain size scale is not complete, as very-fine and very-coarse sand are not present. (D) Coarse-resolution graphic log (modified from Thompson et al., 2015) aimed at characterizing the entire fill of a sedimentary basin. 
structures between studies (cf. Rossi et al., 2017). A further difficulty is whether to record the occurrence or the thickness of such features, which is often ambiguous in graphic $\log$ data.

Many geologists spend weeks in the field carefully measuring and logging stratigraphic sections at fine-scale, and then digitally retracing the logs in the office using vectorgraphics-editor software (e.g., Inkscape is a free, opensource option). However, this drawing is rarely acceptable for publication because of the format and detail, so logs are commonly re-drawn yet again with less detail to serve as a figure in a publication. Neither of these graphic-log drawings are truly "digital"-in other words, the fine-scale data (e.g., thickness, grain size, sedimentary structures) that may have taken days or weeks to collect is never captured in a tabular format that is machine-readable (e.g., a comma-separated-values (csv) file). So, while tens of thousands of meters of graphic logs measured at fine scale exist to quantify lithologic heterogeneity and stacking patterns within and between depositional environments, the data contained in the graphic logs is rarely digital and available for comparative analysis.

\section{DIGITALIZATION AND ANALYSIS OF GRAPHIC LOGS}

A drawing of a graphic log (e.g., a core description traced using Inkscape) is unstructured and cannot be mined easily for quantitative purposes. Digitalization in this paper refers to tabulating the data (e.g., thickness, grain size, sedimentary structures) so that it is structured and machinereadable. The following sections describe open-source software currently available or introduced by this paper (Sec. 3.1) to natively collect digital graphic logs in the field using a computer or tablet, (Sec. 3.2) digitize existing but 'analog' graphic logs (i.e., from a publication or field notebook), and (Sec. 3.3) plot and analyze digital graphic log data.

\subsection{Digital collection of graphic log data}

Many software packages exist to natively collect digital graphic log data, where the data is stored in a structured, tabular format (e.g., a .csv file). While we do not advocate for any particular software over another, there are multiple open-source and free (i.e., no cost) options (Table 1) and we focus on these open-source options while acknowledging there are many closed-source options available. SedLog, developed by researchers at Royal Holloway University (Zervas et al., 2009), runs on Windows and Mac operating systems, and while more than ten years old, contains all the necessary functionality to natively collect digital data. In terms of apps for mobile operating systems, an open-source Android app called StratLogger (Table 1) has simplistic functionality that can be used to collect digital graphic log data, including thickness, grain size, and image data. There is also an NSF-sponsored initiative underway called Strabo (https:/ / www.strabospot.org) that aims to synthesize the collection of digital graphic log data with both desktop and mobile platforms (Duncan et al., 2021).
In addition to the open-source options mentioned above, numerous closed-source, fee-based software packages are available. Most of these packages are focused on the petroleum and economic/ore geology industries and thus have varying functionality depending on the audience. Commonly used closed-source software for creating and displaying graphic logs include CoreCAD, DigitCore, EasyCore, LithoHero, Geologix, GeoticLog, LogPlot, and WellCAD.

\subsection{Purpose-built stratigraphic digitizers (StratCorePro- cessor and stRat stat)}

The afore-mentioned software are used to create digitally native graphic logs and are most useful when collecting new data. However, these software generally do not allow a convenient way to record complex, non-linear grain-size changes within a lithologic unit. Furthermore, for most existing and published logs, this structured tabular data (e.g., spreadsheet of thickness, grain size, other features) does not exist, as the logs are hand-drawn. Because of the need to digitize these existing logs that include complex grain-size trends, we present two purpose-built graphiclog digitizers that accelerate the collection of digital data: StratCoreProcessor (written in MATLAB) and stRat stat (written in $\mathbf{R}$ ) (Table 1). With this paper, we release the digitizers as well as functions that (1) create plots of the graphic logs, (2) compute summary statistics (e.g., net-to-gross, amalgamation ratio sensu Romans et al., 2009) and (3) export to a .csv file that is easily importable into litholog for exploratory data analysis.

These digitizers were created to collect and compile large graphic log datasets and leverage statistical methods to analyze patterns of bed thickness, grain size, and stacking variability. While there is not currently a graphic-log digitizer written in Python, it would be a welcome addition to these two existing digitizers. There are also numerous, more generalized digitizers that use color recognition to convert images to data (e.g., WebPlotDigitizer, Engauge Digitizer, PlotDigitizer) but are not meant specifically for graphic logs, making the data collection and storage considerably more cumbersome. We advocate for utilizing one of the two graphic-log specific solutions for digitizing legacy logs but recognize that these other digitizers may be useful to automate data collection for legacy datasets that have been color-coded by lithology or facies.

To convert a graphic log to structured tabular data using these software packages, one needs to obtain a highresolution image of the graphic log, either scanned from a field notebook, or saved as an image file (e.g., .png or .tif) from a drafting program. Both StratCoreProcessor and stRat stat operate through graphical user interfaces (GUIs) to ensure that users don't have to be proficient in MATLAB or $\mathbf{R}$ to digitize graphic logs. In both packages, the same workflow is followed in order to convert an image of a graphic log into tabular data: (1) launch the GUI and load an image of a graphic $\log$, (2) set the axes of the graphic $\log$, both grain size (x) and thickness (y), (3) digitize grain 


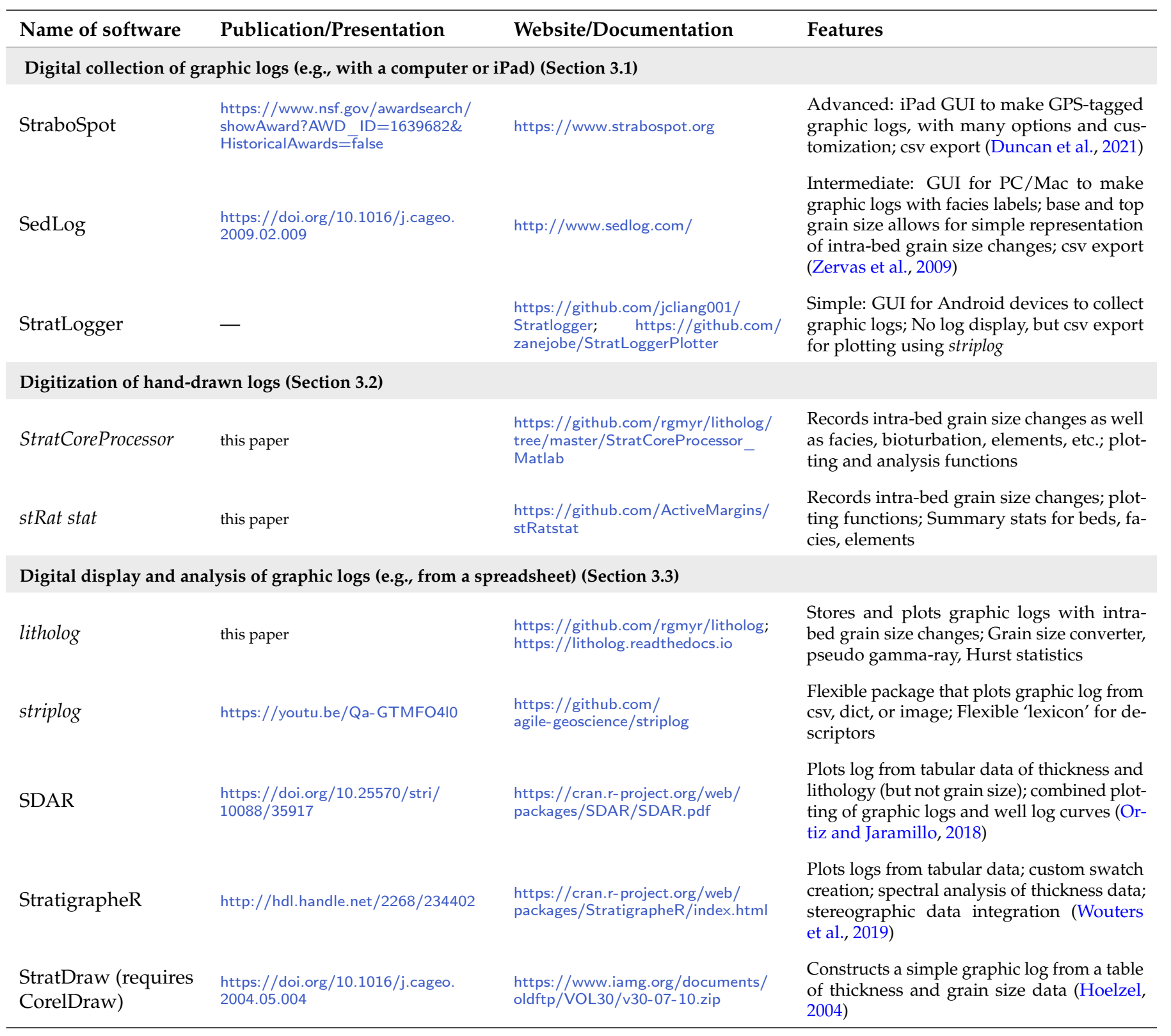

Table 1 List of open-source software for collecting, digitizing, and plotting/analyzing graphic logs.

\begin{tabular}{|c|c|c|c|c|c|}
\hline $\begin{array}{l}\text { Stratigraphic } \\
\text { height at bed top } \\
(\mathrm{m})\end{array}$ & $\begin{array}{l}\text { Thickness } \\
\text { (m) }\end{array}$ & $\begin{array}{c}\text { Grain size at } \\
\text { top }(\mathrm{mm})\end{array}$ & $\begin{array}{l}\text { Depth values }(\mathrm{m}) \text { for } \\
\text { intra-bed grain size } \\
\text { changes }\end{array}$ & $\begin{array}{c}\text { Grain size values }(\mathrm{mm}) \text { for } \\
\text { intra-bed grain size } \\
\text { changes }\end{array}$ & Notes \\
\hline 2.1 & 0.3 & $\mathrm{NaN}$ & & & $\begin{array}{l}\text { Covered interval (no } \\
\text { intra-bed grain size } \\
\text { changes) }\end{array}$ \\
\hline 1.8 & 0.7 & 80 & {$[1.1,1.2,1.5,1.8]$} & {$[5,20,30,80]$} & $\begin{array}{l}\text { Conglomerate, } \\
\text { coarsening up }\end{array}$ \\
\hline 1.1 & 0.1 & 0.02 & & & $\begin{array}{l}\text { Mud (no intra-bed } \\
\text { grain size changes) }\end{array}$ \\
\hline 1.0 & 1.0 & 0.0884 & {$[0,0.05,0.1,0.9,1]$} & {$[1,0.5,0.25,0.125,0.0884]$} & Sand, fining up \\
\hline
\end{tabular}

Table 2 Example spreadsheet for structured, tabular, graphic log data. Only the leftmost three columns are necessary to plot and analyze a basic graphic log using litholog, but the intra-bed grain size columns are necessary to include to generate the graphic log shown in Figure 2. 
size profiles and bed 'tops' from the image manually via mouse clicks, and (4) save the data file. This may sound tedious and time consuming, but in our experience, it is a straightforward (and cathartic) process that takes less than an hour to digitize a $\sim 50-\mathrm{m}$ detailed stratigraphic section, yielding hundreds or thousands of data points. In addition to thickness and grain size, much more data can also be digitized, including sedimentary structures, bioturbation, and facies; the digitizers could be configured/modified to digitize other features of interest as well.

Both software packages have functionality to plot digitized graphic logs; we have found that exporting the plotted graphic log as a line-art file (e.g., .eps or .svg) and 'beautifying' it in drafting software saves significant time as opposed to tracing the whole log manually using drafting software. In addition to saving time, going directly from a field notebook to the digitizer saves a step and also results in the generation of quantified data about the graphic log in question. Both packages also compute summary statistics (e.g., net-to-gross, amalgamation ratio), and stRat stat leverages $\mathbf{R}$ packages that allow for the rapid calculation of summary statistics on demarcated beds and three levels of stratigraphic hierarchy (e.g., facies, elements, element sets sensu Macauley and Hubbard, 2013), as well as the ability to join and summarize both discrete and continuous data (e.g., petrophysical samples, well logs) over these intervals.

\section{3 litholog package}

Many of the package above allow for plotting and simple analysis of a single graphic-log. However, comparing logs from different locations or depositional environments is of great value (e.g., Sadler, 1982, Sylvester and Lowe, 2004), and there is an abundance of data available to do so, but few tools with which to complete these analyses. We present the litholog Python package and associated data schema (i.e., format) (Table 2) that standardizes the structure of tabular data needed to store, plot, and analyze graphic logs. litholog is a Python package-level extension of striplog (Hall, 2015; https:/ / github.com/agilegeoscience/striplog) that allows for storage and plotting of intra-bed grain-size variability (Fig. 2) and the computation of graphic-log summary statistics (e.g., net-to-gross, amalgamation ratio). The only data necessary to digitally store and plot a graphic log are a structured tabular spreadsheet that includes the thickness and grain size of each event-bed or lithologic unit (Table 2; Fig. 2). Even with only thickness and grain size digitized from a graphic log, important differences between depositional processes and environments have been identified (e.g., Sadler, 1982, Reynolds, 2019).

In the litholog package, data from a graphic log are stored in the classes Bed and BedSequence; Beds store data from one lithologic unit/interval (e.g., stratigraphic height/depth, thickness, grain size), and a BedSequence is a collection of Beds that in stratigraphic order; BedSequence is the digital equivalent of a graphic log. However, most graphic logs present much more information than simply thickness and grain size; thus, the Bed class is flex-

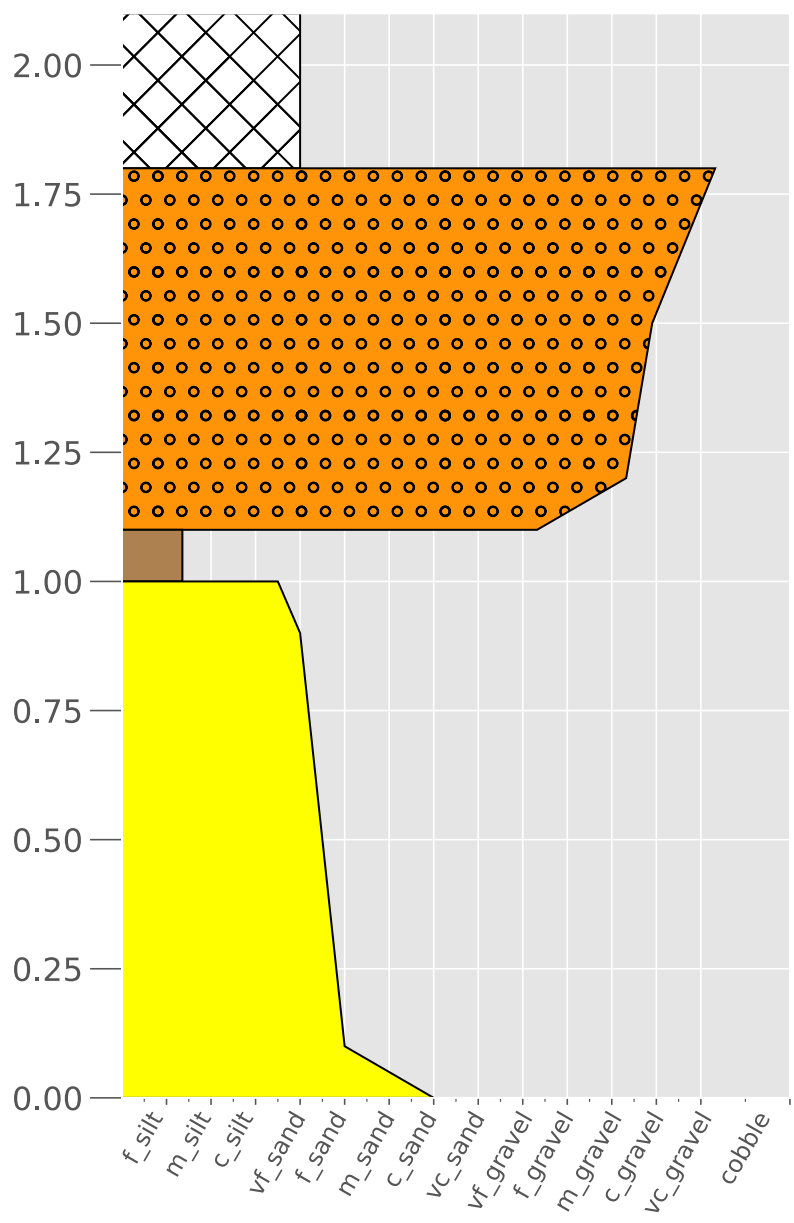

Figure 2: Graphic log plot output from litholog using the data from Table 2.

ible and can store the location and thickness of any data deemed important (e.g., bed boundary types, sedimentary structures, fossil content, ichnofauna, paleocurrent indicators, facies). If this data exists in a graphic log that is being digitized, we suggest recording the thickness of these features (rather than just their occurrence) so that the features of the graphic log are digitized in true fidelity. An important component of any digitized graphic log is the ability for a single 'bed' or sedimentation unit (textitsensu Lowe, 1982) to have vertical changes in grain size (e.g., Figs. 2, 3). These vertical grain-size changes can inform depositional process and environment (e.g., Walker, 1965, Sadler, 1982, Hiscott et al., 1997, Sylvester and Lowe, 2004, Kane et al., 2017). In previous software, such as SedLog (Zervas et al., 2009), this is accomplished with the option to choose a different grain size for the base and top of each bed, assuming a linear rate of fining from base to top. However, grainsize changes are often distributed unequally through the thickness of the bed (e.g., Fig. 2), and we advocate for a data array in the Bed class consisting of grain-size $(x)$ and height (y) pairs that describe the vertical rate of grain-size change for each bed (Table 2). For modeling purposes, an equation could be fitted to these data to inform particle 
settling dynamics of event-beds or the distribution of reservoir properties within beds, but the development of such methods is beyond the scope of this study.

In addition to storing, organizing, and plotting graphic logs as Beds and BedSequences, litholog also includes utilities for (1) transforming grain size data between text, linear units (e.g., $\mathrm{mm}$ ) and $\log _{2}$ units (e.g., Psi), (2) calculating summary statistics at the litholog level (e.g., net-to-gross, amalgamation ratio), (3) plotting a pseudo gamma-ray curve, and (3) analyzing facies clustering using Hurst statistics. A full description of the capabilities of litholog can be found in the documentation (https://litholog.readthedocs.io).

\section{DISCUSSION}

\subsection{Quantitative insights from digitized graphic logs}

Extracting graphic log data into a structured, tabular format (e.g., Table 2) allows for straight-forward calculation of descriptive and/or comparative statistics as well as rapid visualization of the data using any of the field(s) in the schema. The demo data included in litholog include 13 logs with 1056 'beds' obtained from two published papers (Jobe et al., 2010, 2012) that document turbidites from the Cerro Toro (Chile), Skoorsteenberg (South Africa), Mount Messenger (New Zealand) formations as well as a core description from the subsurface Gulf of Mexico (Jobe et al., 2012). Combining all 13 logs together irrespective of location, the gravel-bed, sand-bed, and mud-interval (sensu Fryer and Jobe, 2019) thicknesses have quite different distributions and are easily visualized (Fig. 4).

Alternatively, these distributions can be compared across multiple outcrop locales. For example, Figure 5 compares the gravel, sand, and mud thickness data from graphic logs from the Sierra del Toro (SDT) locale of the Cerro Toro Formation and the Kleine Reit Fontein (KRF) locale of the Skoorsteenberg Formation. KRF has thinner mud intervals than does SDT (Fig. 5), easily discernible by visual inspection (Fig. 5). This is confirmed through a KolmogorovSmirnov (KS) test that demonstrates a significant difference between the SDT and KRF mud-interval thickness distributions ( $p=1 \times 10-12)$. Though the inter-quartile sand thicknesses seem broadly similar between SDT and KRF (Fig. 5), a KS-test also demonstrates a significant difference between the two distributions ( $p=0.00013$ ). These statistics could be compared from log to log within or between formations, depending on the research question.

Grain size data is also easily quantified and visualized using litholog. Figure 6 shows the mean grain size for sand and conglomerate beds from five graphic logs from the SDT locale. The mean grain size for each bed was calculated using a thickness-weighted mean, and the kernel density estimate shows the distribution of mean grain size for all the beds from one $\log$ (Fig. 6). Trends in mean grain size could easily be compared spatially using this data (e.g., Malkowski et al., 2018), as could the potential for bias during data collection or digitization (e.g., the log with much finer-grained sand than the other, Fig. 6).

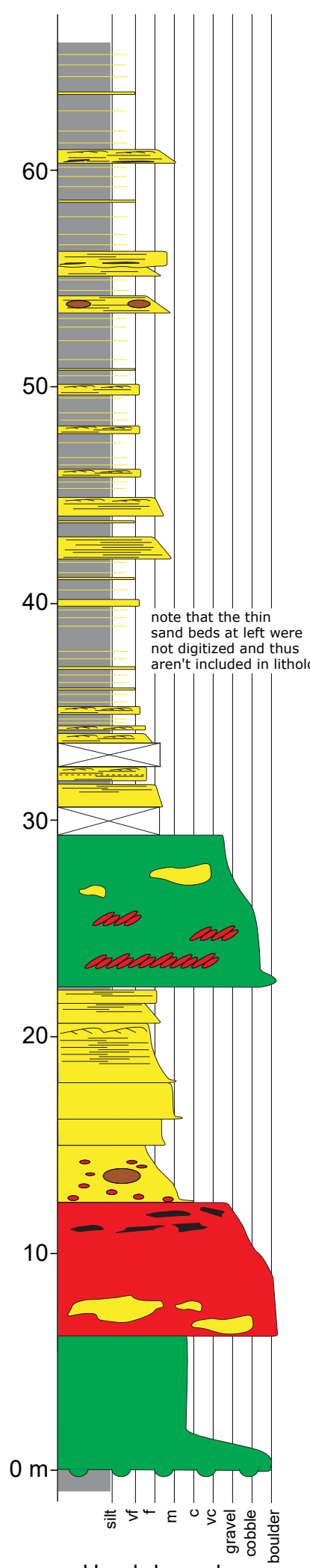

Hand-drawn log

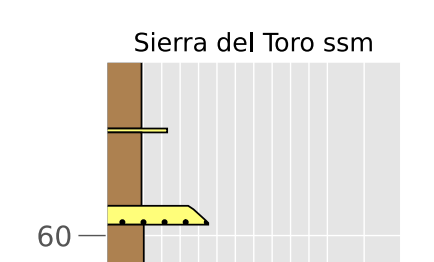




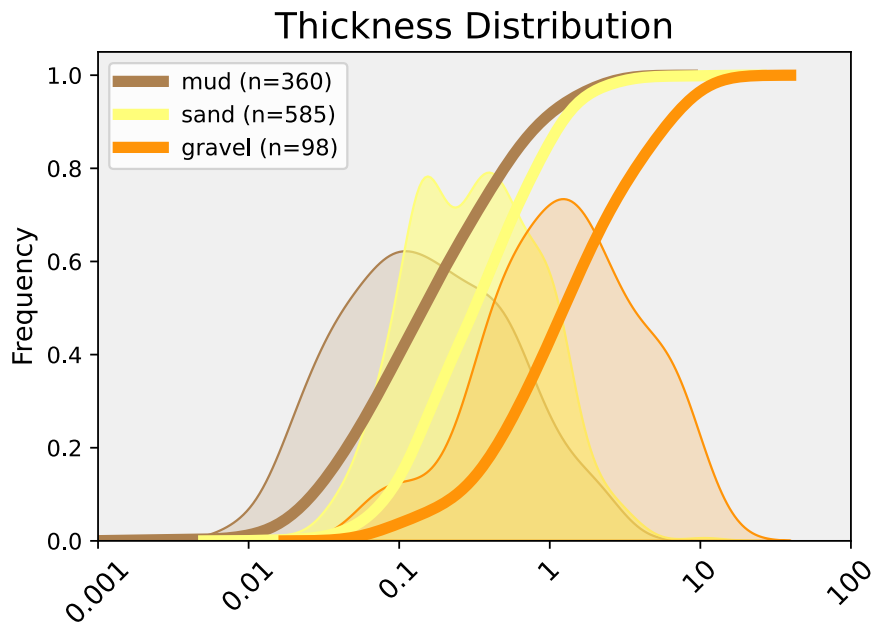

Figure 4: Gravel-bed, sand-bed, and mud-interval thickness distributions from the demo dataset included in litholog. Shaded polygons are kernel density estimates (KDEs) and the thicker lines are cumulative distribution functions (CDFs).

\subsection{Graphic logs: Suggested logging template and style \\ 4.2.1 Template}

The standardization and quantification of graphic log data may seem pedantic and onerous, but it will allow our community to quickly build a large database of stratigraphic sections and start comparing data from all over the world. These comparisons can only happen if the sedimentary geology community is rigorous about data standards/schema and digitalization, particularly grain-size data (see subsequent section). This paper will focus on fine-scale (often termed "bed-scale") graphic logs, where every lithologic change or sedimentation unit (i.e., each bed) is depicted (e.g., Fig. 1B). For graphic logs drawn at coarser scale, the inevitable simplifying and lumping that occurs (while useful for that scale of work) means that the data derived from coarsely measured graphic logs is more subjective and less useful for detailed classification of depositional (sub) environments (Fig. 1C, D). If graphic logs are drawn schematically to save time in the field, we ask that those logs include some text or symbol to denote where the logs are schematic (Fig. 1C); this will enable accurate digitalization during data compilation efforts.

The suggested logging template is shown in Figure 7 (sized to A4 paper; 8.5" $\times 11^{\prime \prime}$ version included in the Supplemental Documentation). There are 100 equally spaced horizontal lines for characterizing stratigraphic thickness, with a bold line every five lines (Fig. 7). These divisions make the template convenient to $\log$ at a scale of $1,2,5$, and $10 \mathrm{~m}$ per page. We recommend measuring at one of these scales (and no coarser than $10 \mathrm{~m}$ per page) to appropriately capture fine-scale (i.e., bed-by-bed) heterogeneity. Again, in a coarser-scale study (e.g., formation-scale), we ask that the author annotate the logs to describe how schematic they are drawn.

We suggest the utilization of a standardized color scheme for sand and mud (Figs. 2, 3, and 8), which will allow digitalization of raster graphic logs (e.g., from an image) using image-recognition methods (e.g., Pankaj et al., 2017). We suggest colors to be sand as 'xkcd:LightYellow' (RGB 255254122 or hex color \#fffe7a) and mud as 'xkcd:LightBrown' (RGB 173129 80, hex color \#ad8150) and gravel as 'xkcd:tangerine' (RGB 255148 8, hex color \#ff9408).

\subsubsection{Grain size}

\section{The Wentworth scale and $\Psi$ (Psi) units}

Measuring grain size is perhaps the most subjective action when logging, and there can be confusion about grainsize terminology and grain-size boundaries. We advocate for using the Wentworth scale (Wentworth, 1922), in which the various grain size classes are separated by factors of 2 , using a reference grain diameter of $1 \mathrm{~mm}$. In other words, doubling or halving $1 \mathrm{~mm}$ gives coarser and finer grainsize classes, respectively (Table 3; also see Williams et al., 2006). This scale easily adapts to the Phi $(\Phi)$ or Psi ( $\Psi)$ logarithmic transformation using a logarithm with base 2 (i.e., doubling or halving; Table 3). The Phi unit is defined as $\Phi=\log _{2}\left(D / D_{0}\right)$ where $D$ is a grain size diameter in millimeters, and $D_{0}$ is the reference grain diameter of 1 $\mathrm{mm}$. The $\Phi$ scale is traditionally used to represent grain size divisions (Krumbein, 1934), but $\Phi$ is not intuitive because $\Phi$ units decrease as grain size increases (Table 3). Rather, it is more convenient to express grain-size measurements in units of Psi $(\Psi)$, where $\Psi=-\Phi$, and thus $\Psi=\log _{2}\left(D / D_{0}\right)$ (Parker and Andrews, 1985). The $\Psi$ scale results in grain size divisions that increase with increasing grain size, which is much more intuitive (Table 3 ).

$$
\Psi=-\Phi=\log _{2} \frac{D}{D_{0}}
$$

\section{Field-estimation of grain size}

Grain size, while best quantified with laboratory techniques (see review by Syvitski et al., 1991), is generally estimated in the field by using a hand lens to compare the rock to a grain size card that is split in $1 / 2 \Psi$ units (Table 3). Choosing a $1 / 2 \Psi$ unit, however, can be difficult and subjective, as grain size in sandstones is typically log-normal (Udden, 1914, Spencer, 1963, Visher, 1969) and there can be significant variability in roundness, sorting, and cementation that may affect the visual appearance of the sample (Leeder, 1982). Many grain size cards are also poorly printed and thus make distinguishing smaller grain sizes very difficult. We prefer using the grain size cards from SciOptic USA (Katy, Texas) because they are made from durable transparent plastic with ink that does not rub off easily. There are two versions of the SciOptic grain size card, and we prefer the larger-format card, which includes gravel divisions and can accurately size grains from lower very fine sand $(\Psi=-4)$ to small cobbles $(\Psi=6)$. We recommend measuring and drawing the modal grain size, which admittedly is a somewhat subjective approximation 


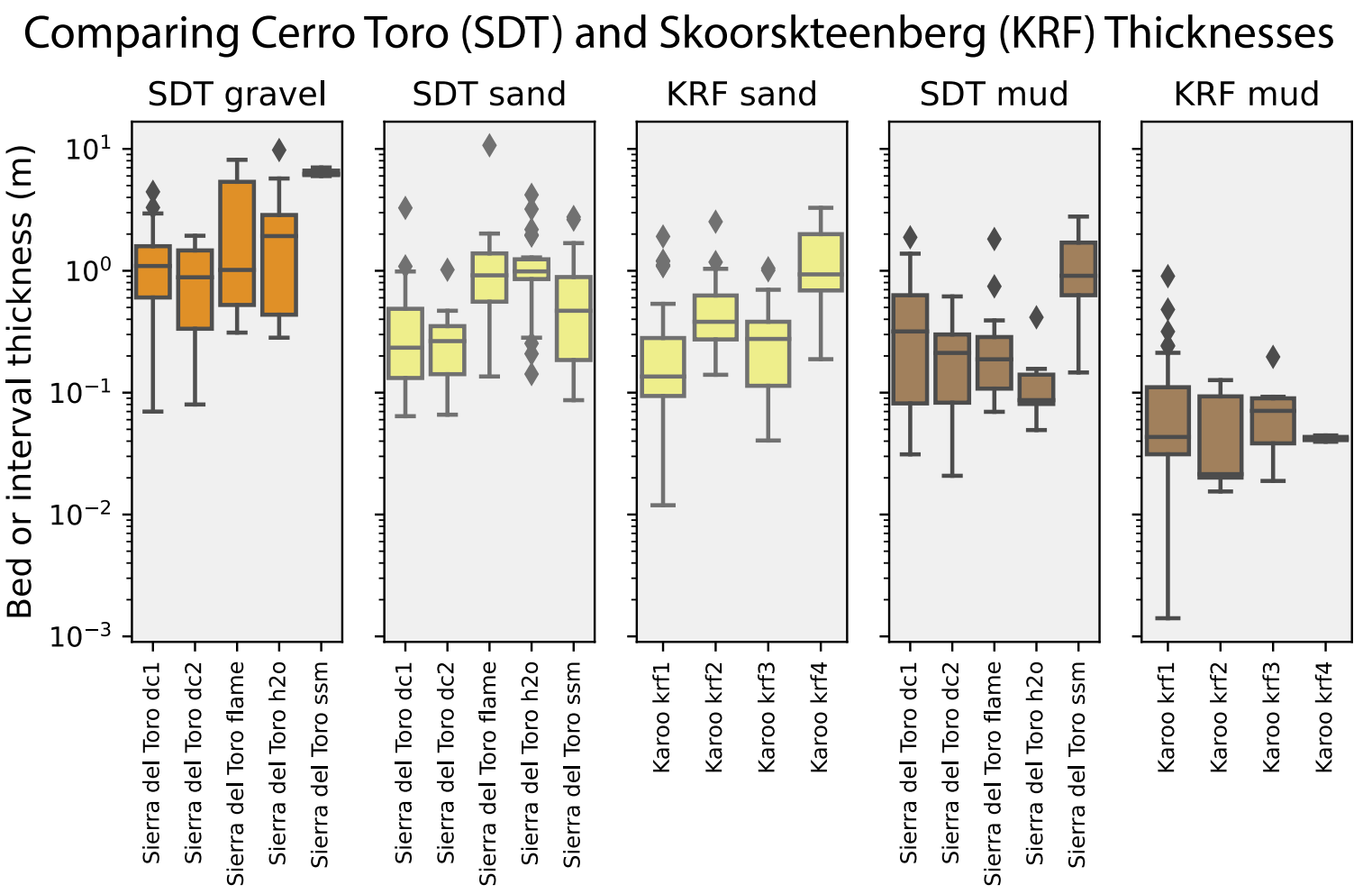

Figure 5: Box plot comparison of thickness data from the Sierra del Toro (SDT) locale of the Cerro Toro Formation (Chile) and the Kleine Reit Fontein (KRF) locale of the Skoorsteenberg Formation (South Africa).

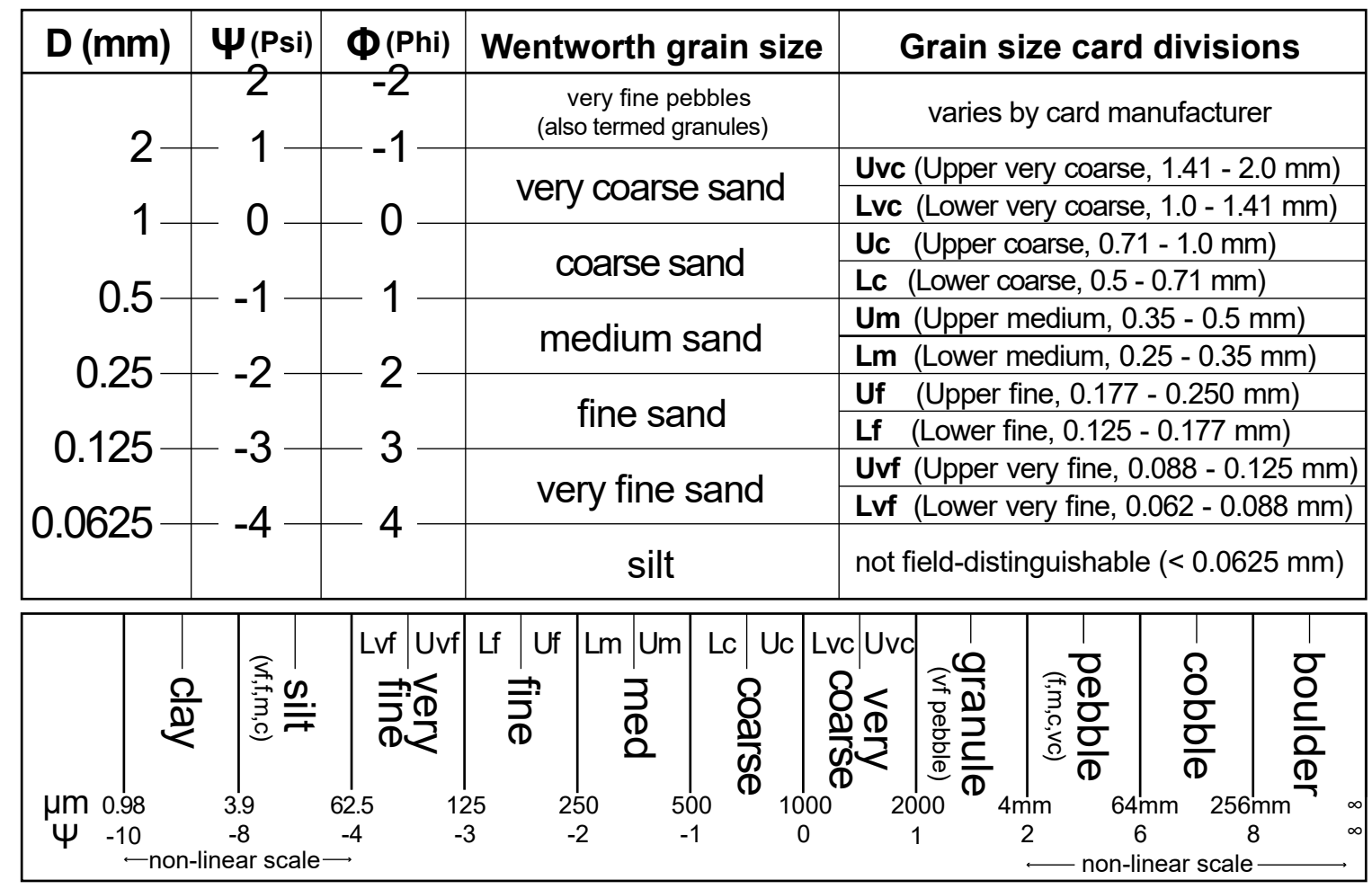

Table 3: Wentworth grain-size classes that are most commonly used in sedimentary geology, and their respective Psi ( $\Psi$ and Phi ( $\Phi$ ) values. We recommend using $\Psi$ units, as $\Psi$ increases with increasing grain size, which is more intuitive than $\Phi$ For a similar version of this chart, see Williams et al. (2006) or Figure 3 of Farrell et al. (2013). 


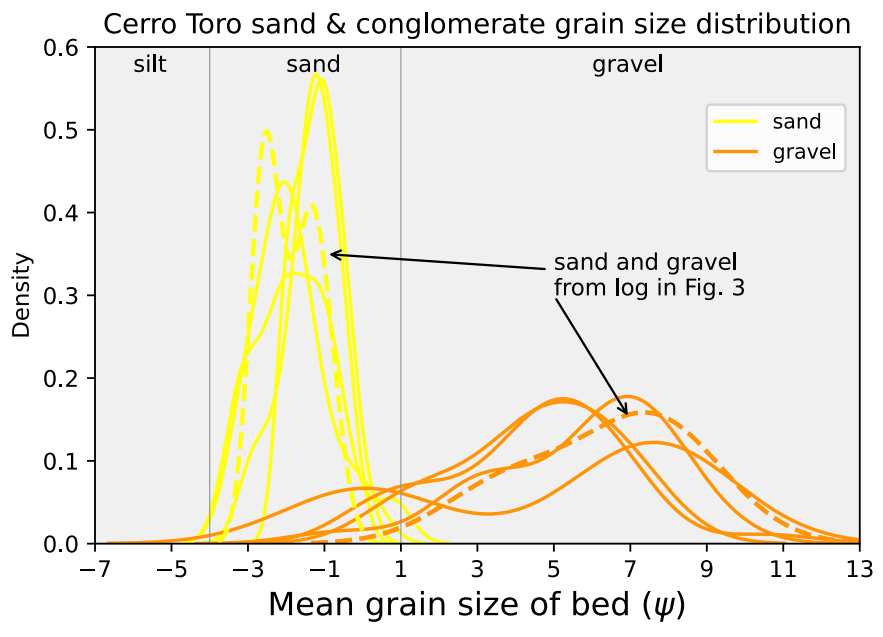

Figure 6: Kernel density estimates (KDE) of grain size data from 5 graphic logs from the Sierra del Toro (SDT) locale of the Cerro Toro Formation (Chile). Each KDE is the grain-size distribution from one graphic log.

using a hand lens and a grain size card. This modal estimate likely underestimates the mean grain size, as grain size distributions tend to be log-normal in natural systems (Folk and Ward, 1957, Irani and Callis, 1963). If possible, it is also very useful to document the maximum grain size as a separate line on the logging template (e.g., Chapin and Keller, 2007). Whatever the method or template used, it is important to indicate/describe that template/method in a figure caption or methods section accompanying the graphic log data, or even include a blank logging sheet in the supplement with a description of logging methods.

In systems with mixed carbonate-siliciclastic input, the grain-size estimation problem is only exacerbated due to carbonate allochem diversity and diagenetic processes (Folk, 1974, Chiarella et al., 2017). In carbonate-dominated systems, grain size is typically not recorded in a comparable manner to clastic environments, but rather a textural classification is used on the $\mathrm{x}$-axis of a graphic log (see discussion in Lokier and Al Junaibi, 2016). New studies have emphasized the importance of carbonate grain hydrodynamics (e.g., de Kruijf et al., 2021), and we advocate for collection of carbonate grain-size data that is similar to clastic systems to allow for quantitative comparison in the future.

\section{How to draw grain size and thickness}

When drawing a lithologic unit (i.e., bed), the thickness of that unit is specified by the y-axis and the grain size (or grain-size trend) is specified by the $\mathrm{x}$-axis (Fig. 8A). For thickness measurements, we advocate using the metric system (centimeters or meters as the vertical axis), as it makes measuring at various scales much simpler (e.g., how many inches is a tenth of a foot if logging at 1:10?-perhaps an Americentric problem). While drawing a unit of thickness is straightforward, grain size is where most of the subjectivity exists in a graphic log, as many sedimentary geologists draw grain size differently. For example, if a hand lens and grain size card are used to estimate a grain size of lower medium sand (250-375 $\mu \mathrm{m}$ ), should one plot that point on the line separating fine and medium, or in the center of the lower medium bin? This may seem like a pedantic point, but when digitizing hand-drawn logs, the wrong convention can misrepresent grain size by $1 / 2 \Psi$ or more, which is often the difference between lithofacies and/or subenvironments in clastic systems (Visher, 1969, Hawie et al., 2019). Thus, we propose the following methodology for drawing grain size on the suggested template (Fig. 8).

Since grain size is only estimated to the nearest $1 / 2 \Psi$ increment (Table 3), grain size should be drawn in the center of the appropriate $1 / 2 \Psi$ bin on a graphic log. The red boxes in Figure 8A denote the uncertainty associated with typical in-the-field grain size measurement (e.g., 0.125 to 0.177 $\mathrm{mm}$, or -3 to $-2.5 \Psi$ or lower fine-grained sand). For example, a $10-\mathrm{cm}$ thick sandstone that has a modal grain size of lower fine, but has a 1-cm basal lag of upper coarse sand is drawn as shown in Figure 8A. To characterize grain size more accurately, quantitative granulometry (e.g., Syvitski et al., 1991) would be necessary.

Importantly, there are equal-width bins for each sand grain size class (i.e., each $1 / 2 \Psi$ unit) on the template (Fig. 7), and micron values separate the classes. This equal-width binning has three main advantages over arbitrary-width bins: (1) the bins are intuitive as they match most grain size cards and most closely resemble the Wentworth $\log _{2}$ grain size scale, (2) grain size can be drawn to the nearest $1 / 2 \Psi$ increment, as described above; and (3) it allows for simple and objective digitalization of sand grain size from a pencil-drawn log using a simple logarithmic transform of the $x$-axis. This third advantage is important, as geologists will often modify the grain size $\mathrm{x}$-axis for their field area or scale of work (e.g., different widths for different grain size fractions) or omit grain size classes altogether (e.g., Fig. 1C, D), which makes digitizing grain size very difficult, or even impossible. For mudstones, even though silt and clay both contain multiple Phi-units, we advocate drawing the same width as the sand bins (Fig. 7); this is done for practicality, as sub-units of silt and clay are generally not field-identifiable. The same logic stands for pebble, cobble, and boulder grain sizes (Fig. 7). For those geologists studying very coarse-grained or very fine-grained systems, another logging sheet may be appropriate.

When digitizing pencil-drawn logs, the thickness should be discretized only to the resolution at which the log was drawn (e.g., $1 \mathrm{~cm}$ for the example in Fig. 8). This is practical to avoid oversampling, and allows each discrete thickness unit to be assigned a grain size range (i.e., a $1 / 2 \Psi$ increment). Using this range rather than a single grain-size value for each discretized thickness bin is a more honest representation of the field-collected data, and it makes uncertainty propagation during a comparative analysis more realistic, especially when comparing logs from different authors or among templates with variable grain size axes. If granulometric data are present, this grain-size uncertainty can be quantified and perhaps reduced. 


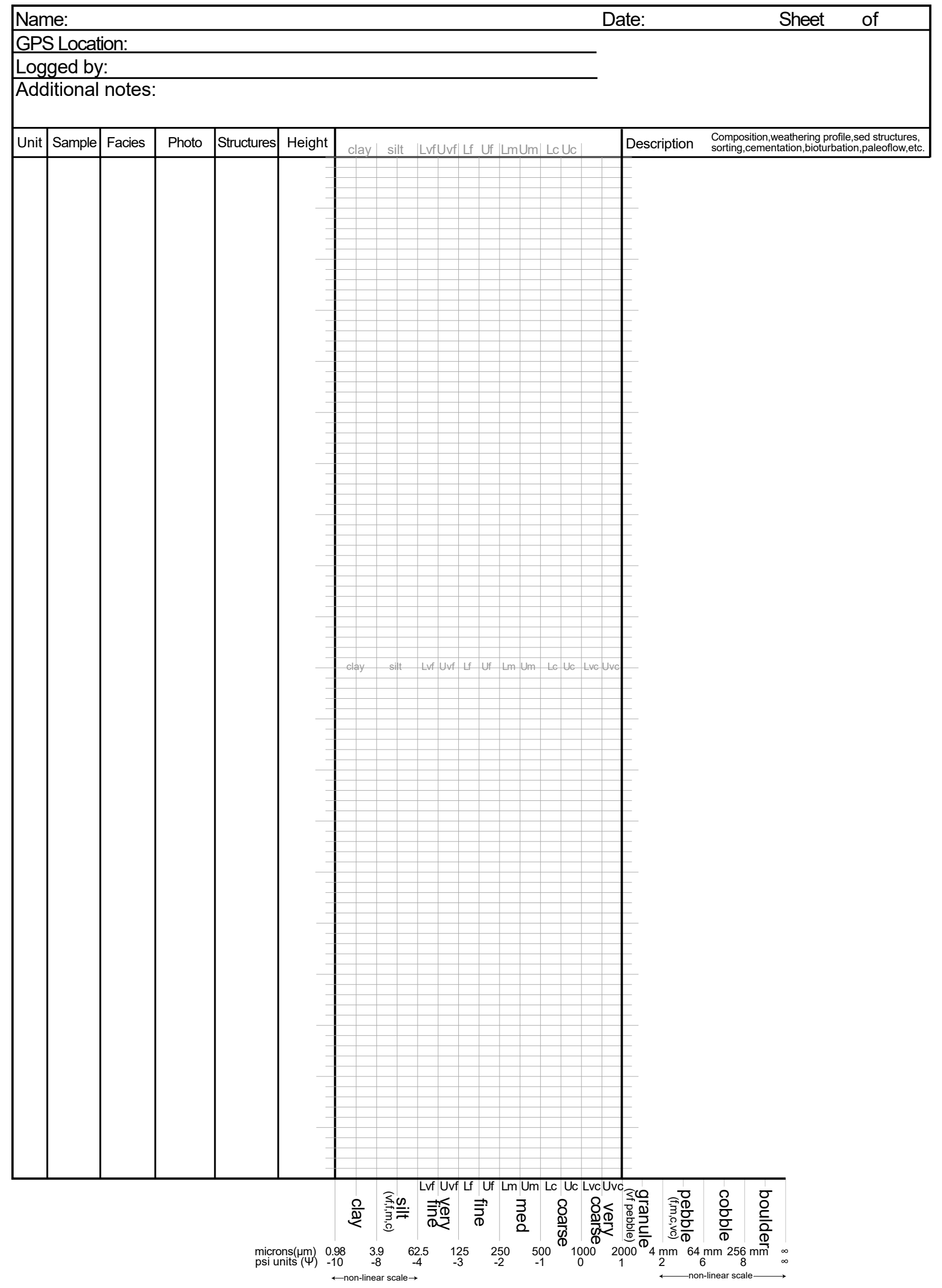

Figure 7: Blank logging template (see Supplemental Documentation for printable A4, Letter, and Tabloid sizes). Original source of this logging sheet is uncertain; see similar templates in Boyles et al. (1986), Johnson (1992), Farrell et al. (2013). 


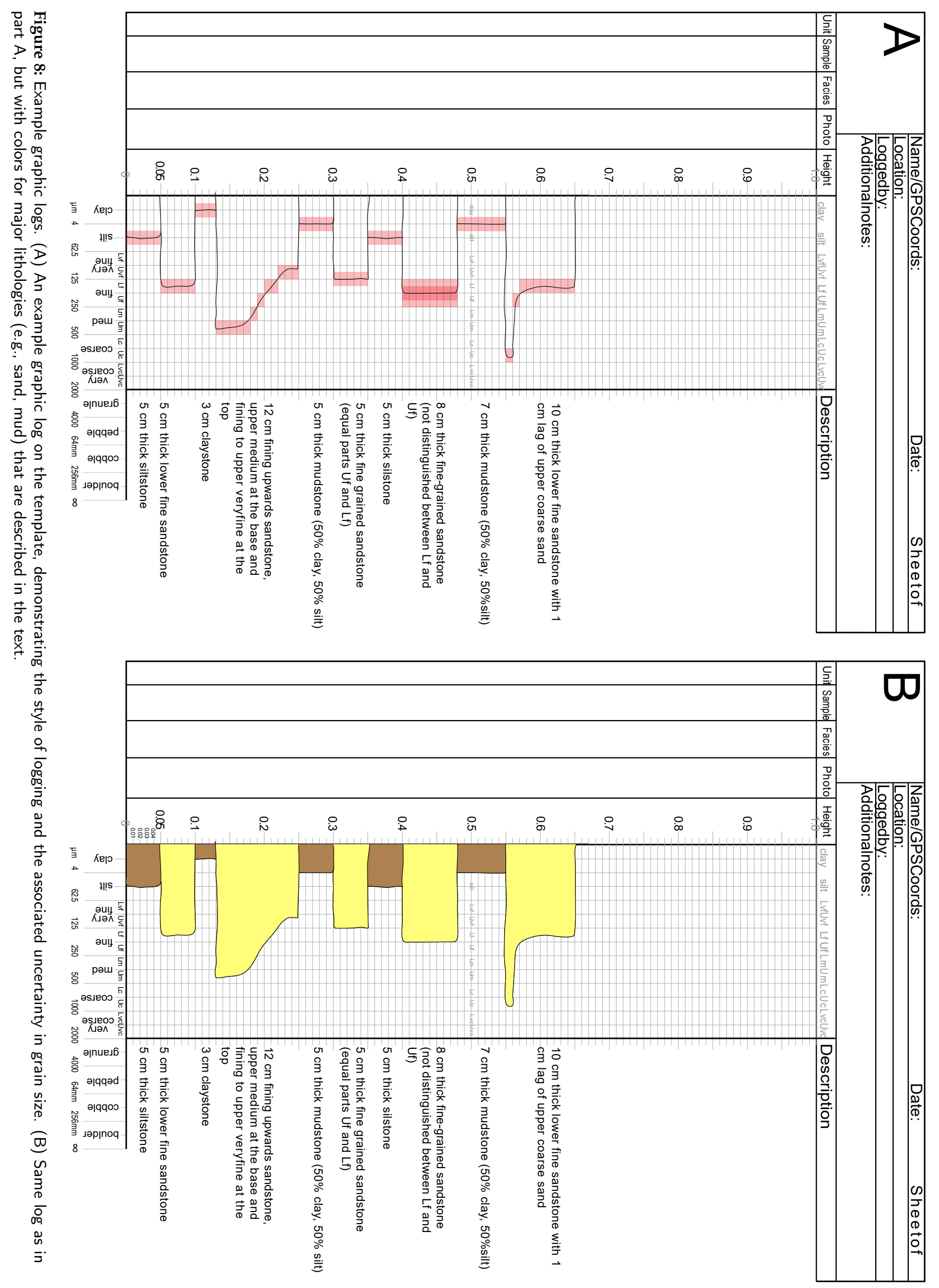


Contacts between lithologic units or beds can be characterized as gradational, sharp, or erosional (e.g., Zervas et al., 2009). We choose not to incorporate bed boundaries, primary sedimentary structures, ichno-structures, or diagenetic features (e.g., concretions) into a standardized schema, due to their vast variety and variability. We strongly suggest authors to provide a detailed legend of their symbology of structures and a note about what was not recorded (e.g., bioturbation). Several existing symbology libraries exist:

- https://www.iogp.org/blog/geomatics/ shell-releases-its-standard-legend-to-industry-and-academia/

- https://esri-styles.maps.arcgis.com/home/item.html?id= 54f7adc786e24fed9e9ff6ab9731462b

- https://github.com/afrigeri/geologic-symbols-qgis

- https://www.npd.no/globalassets/2-force/2020/ nettverksgrupper/geostandard_final.pdf

- https://blogs.otago.ac.nz/si-geology/ resources/illustrationgraphics-resources/ usgs-inkscape-pack-instructions-and-download-link/

- https://pubs.usgs.gov/tm/2006/11A02/

\subsection{A call for quantitative data collection}

Sedimentary geology is oftentimes a qualitative science, particularly when dealing with descriptions of depositional environments from outcrop and core data. However, ample quantitative data is collected using graphic logs (e.g., bed thickness, grain size, sedimentary structures, stacking patterns, bioturbation index) to help quantify and bolster our interpretations. The resulting data has immense value for quantifying (and predicting) depositional environment characteristics (e.g., Tőkés and Patacci, 2018, Fryer and Jobe, 2019, Vento, 2020).

We advocate for the careful collection and digitalization of graphic logs; indeed, the adoption of these methods across the entire sedimentary geology community would generate a large and ever-growing source of quantitative, classified, machine-readable data that can be harnessed for statistical analysis and machine-learning purposes. An obvious use of this data would be to use well-constrained examples as training data for assessing depositional-environment-interpretation uncertainty in ambiguous or data-limited cases (e.g., subsurface core data). Lastly, a growing database of fine-scale data from graphic logs will aid in parameterizing reservoir models for water-resource, critical mineral, and hydrocarbon-reservoir evaluation.

\section{CONCLUSIONS}

Graphic logs are the ubiquitous method for measuring and characterizing the stratigraphic record, but most of that data remains inaccessible and analog in nature. We present open-source software to (1) digitize the vast library of graphic-log data present in field books, publications, and theses, and (2) store, plot, and analyze that data in a structured, tabular format. Digitizers in MATLAB and $\mathbf{R}$ are provided for log digitization, and the Python package litholog aids in data storage, plotting, manipulation, and analysis. In order to standardize data collection, we also provide a graphic-log template for measuring stratigraphic sections, and discuss the importance of accurately reproducing the grain-size scale on logging paper and its downstream effects on digitization and grain-size assignment for a particular depth interval. While we support the traditional methods of logging a section, we do advocate for drawing logs in a way that allows for objective digitization. Lastly, we advocate for the digitization and quantitative analysis of graphic-log data to help quantify observations and interpretations in sedimentary geology (e.g., depositional (sub)environments and facies analysis). We hope that the resources presented in this study can aid in new research directions and discoveries in sedimentary geology.

\section{ACKNOWLEDGMENTS}

We thank Shell for the release of StratCoreProcessor and Sarah Southern for improving its functionality; Luke Pettinga, Rosie Fryer, and Lauren Shumaker for logging template discussions; the slack community of software underground for feedback on litholog. Editor Jenn Pickering and reviewers Neal Auchter, Matt Hall, and Emma Morris helped to focus and improve the manuscript. ZRJ acknowledges support from Chevron through the CoRE center (https: / / core.mines.edu).

\section{Literature Cited}

Allen, J. (1970). Studies in fluviatile sedimentation: A comparison of fining-upwards cyclothems, with special reference to coarse-member composition and interpretation. Journal of Sedimentary Research, 40(1).

Bernhardt, A., Jobe, Z. R., and Lowe, D. R. (2011). Stratigraphic evolution of a submarine channel-lobe complex system in a narrow fairway within the Magallanes foreland basin, Cerro Toro Formation, southern Chile. Marine and Petroleum Geology, 28(3):785-806.

Boulesteix, K., Poyatos-Moré, M., Flint, S. S., Taylor, K. G., Hodgson, D. M., and Hasiotis, S. T. (2019). Transport and deposition of mud in deep-water environments: Processes and stratigraphic implications. Sedimentology, 66(7):2894-2925.

Bouma, A. H. (1962). Sedimentology of some flysch deposits: A graphic approach to facies interpretation. Elsevier Publishing Company.

Boyles, J., Scott, A., and Rine, J. (1986). A logging form for graphic descriptions of core and outcrop. Journal of Sedimentary Research, 56(4).

Bridge, J. S. and Tye, R. S. (2000). Interpreting the dimensions of ancient fluvial channel bars, channels, and channel belts from wireline-logs and cores. AAPG Bulletin, 84(8):1205-1228.

Burgess, P. M. (2016a). Identifying ideal stratigraphic cycles using a quantitative optimization method. Geology, 44(6):443-446.

Burgess, P. M. (2016b). Identifying ordered strata: Evidence, methods, and meaning. Journal of Sedimentary Research, 86(3):148-167.

Chapin, M. and Keller, F. (2007). Channel-fill sandstones at San Clemente State Beach, California, USA. AAPG Studies in Geology 56: Atlas of Deep-Water Outcrops, pages 401-405.

Chen, C. and Hiscott, R. N. (1999). Statistical analysis of facies clustering in submarine-fan turbidite successions. Journal of Sedimentary Research, 69(2):505-517.

Chiarella, D., Longhitano, S. G., and Tropeano, M. (2017). Types of mixing and heterogeneities in siliciclastic-carbonate sediments. Marine and Petroleum Geology, 88:617-627.

Compton, R. R. (1985). Geology in the Field. John Wiley and Sons, New York, NY.

Daniels, B. G., Hubbard, S. M., Romans, B. W., Malkowski, M. A., Matthews, W. A., Bernhardt, A., Kaempfe, S. A., Jobe, Z. R., Fosdick, J. C., Schwartz, T. M., Fildani, A., and Graham, S. A. (2019). Revised chronostratigraphic framework for the Cretaceous Magallanes-Austral 
Basin, Última Esperanza Province, Chile. Journal of South American Earth Sciences, 94(102209).

de Kruijf, M., Slootman, A., de Boer, R. A., and Reijmer, J. J. (2021). On the settling of marine carbonate grains: Review and challenges. EarthScience Reviews, 217(103532).

Duncan, C. J., Chan, M. A., Hajek, E., Kamola, D., Roberts, N. M., Tikoff, B., and Walker, J. D. (2021). Bringing sedimentology and stratigraphy into the StraboSpot data management system. Geosphere, 17(6):1914-1927.

Durkin, P. R., Hubbard, S. M., Boyd, R. L., and Leckie, D. A. (2015). Stratigraphic expression of intra-point-bar erosion and rotation. Journal of Sedimentary Research, 85(10):1238-1257.

Durkin, P. R., Hubbard, S. M., Holbrook, J., and Boyd, R. (2018). Evolution of fluvial meander-belt deposits and implications for the completeness of the stratigraphic record. Geological Society of America Bulletin, 130(56):721-739.

Englert, R. G., Hubbard, S. M., Coutts, D. S., and Matthews, W. A. (2018). Tectonically controlled initiation of contemporaneous deep-water channel systems along a Late Cretaceous continental margin, western British Columbia, Canada. Sedimentology, 65(7):2404-2438.

Falivene, O., Arbués, P., Howell, J., Fernández, O., Cabello, P., Muñoz, J. A., and Cabrera, L. (2006). A FORTRAN program to introduce field-measured sedimentary logs into reservoir modelling packages. Computers \& geosciences, 32(9):1519-1522.

Farrell, K. M., Harris, W. B., Mallinson, D. J., Culver, S. J., Riggs, S. R., Wehmiller, J. F., Moore, J. P., Self-Trail, J. M., and Lautier, J. C. (2013). Graphic logging for interpreting process-generated stratigraphic sequences and aquifer/reservoir potential: with analog shelf to shoreface examples from the Atlantic Coastal Plain Province, USA. Journal of Sedimentary Research, 83(8):723-745.

Folk, R. L. (1974). Petrology of sedimentary rocks: Austin, Texas. Hemphill Publishing Company.

Folk, R. L. and Ward, W. C. (1957). Brazos River bar [Texas]; a study in the significance of grain size parameters. Journal of sedimentary research, 27(1):3-26.

Fryer, R. C. and Jobe, Z. R. (2019). Quantification of the bed-scale architecture of submarine depositional environments. The Depositional Record, 5(2):192-211.

Graham, S., Tolson, R., DeCelles, P., Ingersoll, R., Bargar, E., Caldwell, M., Cavazza, W., Edwards, D., Follo, M., Handschy, J., and Lemke, L. (1986). Provenance modelling as a technique for analysing source terrane evolution and controls on foreland sedimentation. In Foreland Basins, pages 425-436. International Association of Sedimentologists Special Publication 8.

Hall, M. (2015). Striplog: Wrangling 1D subsurface data. https: / / youtu.be/Qa-GTMFO410.

Hansen, L., Callow, R., Kane, I., and Kneller, B. (2017). Differentiating submarine channel-related thin-bedded turbidite facies: Outcrop examples from the Rosario Formation, Mexico. Sedimentary Geology, 358:19-34.

Hawie, N., Covault, J. A., and Sylvester, Z. (2019). Grain-Size and Discharge Controls on Submarine-Fan Depositional Patterns From Forward Stratigraphic Models. Frontiers in Earth Science, 7:334.

Hessler, A. M. and Fildani, A. (2019). Deep-sea fans: tapping into Earth's changing landscapes. Journal of Sedimentary Research, 89(11):1171-1179.

Hiscott, R. N., Hall, F. R., and Pirmez, C. (1997). Turbidity-current overspill from the Amazon Channel: Texture of the silt/sand load, paleoflow from anisotropy of magnetic susceptibility, and implications for flow processes. In Proceedings of the Ocean Drilling Program Scientific Results 155, pages 53-78.

Hoelzel, M. (2004). StratDraw: Automatic generation of stratigraphic sections from tabulated field data. Computers \& geosciences, 30(7):785789.

Hou, P., Wood, L. J., and Jobe, Z. R. (2021). Tectonic-sedimentary interplay of a confined deepwater system in a foreland basin setting: The Pennsylvanian lower Atoka Formation, Ouachita Mountains, USA Journal of Sedimentary Research, 91(7):683-709.

Hubbard, S. M., Jobe, Z. R., Romans, B. W., Covault, J. A., Sylvester, Z., and Fildani, A. (2020). The stratigraphic evolution of a submarine channel: Linking seafloor dynamics to depositional products. Journal of Sedimentary Research, 90(7):673-686.

Irani, R. R. and Callis, C. F. (1963). Particle size: Measurement, interpretation and application. Wiley.

Jackson, R. G. (1976). Depositional model of point bars in the lower
Wabash River. Journal of Sedimentary Research, 46(3):579-594.

Jobe, Z. R., Bernhardt, A., and Lowe, D. R. (2010). Facies and architectural asymmetry in a conglomerate-rich submarine channel fill, Cerro Toro Formation, Sierra del Toro, Magallanes Basin, Chile. Journal of Sedimentary Research, 80(12):1085-1108.

Jobe, Z. R., Lowe, D. R., and Morris, W. R. (2012). Climbing-ripple successions in turbidite systems: Depositional environments, sedimentation rates and accumulation times. Sedimentology, 59(3):867-898.

Johnson, M. (1992). A proposed format for general-purpose comprehensive graphic logs. Sedimentary geology, 81(3-4):289-298.

Kane, I. A. and Pontén, A. S. (2012). Submarine transitional flow deposits in the Paleogene Gulf of Mexico. Geology, 40(12):1119-1122.

Kane, I. A., Pontén, A. S., Vangdal, B., Eggenhuisen, J. T., Hodgson, D. M., and Spychala, Y. T. (2017). The stratigraphic record and processes of turbidity current transformation across deep-marine lobes. Sedimentology, 64(5):1236-1273.

Krumbein, W. C. (1934). Size frequency distributions of sediments. Journal of sedimentary Research, 4(2):65-77.

Leeder, M. (1982). Sedimentology: Process and Product. Harper Collins Academic.

Lokier, S. W. and Al Junaibi, M. (2016). The petrographic description of carbonate facies: Are we all speaking the same language? Sedimentology, 63(7):1843-1885.

Lowe, D. R. (1982). Sediment gravity flows: II, Depositional models with special reference to the deposits of high-density turbidity currents. Journal of sedimentary research, 52(1):279-297.

Macauley, R. V. and Hubbard, S. M. (2013). Slope channel sedimentary processes and stratigraphic stacking, Cretaceous Tres Pasos Formation slope system, Chilean Patagonia. Marine and Petroleum Geology, 41:146162

Malkowski, M. A., Jobe, Z. R., Sharman, G. R., and Graham, S. A. (2018). Down-slope facies variability within deep-water channel systems: Insights from the Upper Cretaceous Cerro Toro Formation, southern Patagonia. Sedimentology, 65(6):1918-1946.

Miall, A. D. (1973). Markov chain analysis applied to an ancient alluvial plain succession. Sedimentology, 20(3):347-364.

Murray, C. J., Lowe, D. R., and Graham, S. A. (1996). Statistical analysis of bed-thickness patterns in a turbidite section from the Great Valley Sequence, Cache Creek, Northern California. Journal of Sedimentary Research, 66(5):900-908.

Mutti, E. and Normark, W. R. (1987). Comparing examples of modern and ancient turbidite systems: problems and concepts. In Marine clastic sedimentology, pages $1-38$. Springer.

Mutti, E. and Ricci Lucchi, F. (1978). Turbidites of the northern Apennines: introduction to facies analysis. International Geology Review, 20(2):125166

Ortiz, J. R. and Jaramillo, C. A. (2018). SDAR: A Toolkit for Stratigraphic Data Analysis in R.

Pankaj, P., Fatema Al, N., Pranav, K., and Amit, K. (2017). Preserving and Securing Legacy Well Log Data. In Abu Dhabi International Petroleum Exhibition \& Conference. OnePetro.

Parker, G. and Andrews, E. (1985). Sorting of bed load sediment by flow in meander bends. Water Resources Research, 21(9):1361-1373.

Pattison, S. A. (2019a). High resolution linkage of channel-coastal plain and shallow marine facies belts, Desert Member to Lower Castlegate Sandstone stratigraphic interval, Book Cliffs, Utah-Colorado, USA Geological Society of America Bulletin, 131(9-10):1643-1672.

Pattison, S. A. (2019b). Using classic outcrops to revise sequence stratigraphic models: reevaluating the Campanian Desert Member (Blackhawk Formation) to lower Castlegate Sandstone interval, Book Cliffs, Utah and Colorado, USA. Geology, 47(1):11-14.

Pierce, C. S., Haughton, P. D., Shannon, P. M., Pulham, A. J., Barker, S. P., and Martinsen, O. J. (2018). Variable character and diverse origin of hybrid event beds in a sandy submarine fan system, Pennsylvanian Ross Sandstone Formation, western Ireland. Sedimentology, 65(3):952992.

Reynolds, T. (2019). "Grain-size bookkeeping," a new aid for siliciclastic systems with examples from paralic environments. Journal of Sedimentary Research, 89(10):976-1016.

Romans, B. W., Hubbard, S. M., and Graham, S. A. (2009). Stratigraphic evolution of an outcropping continental slope system, Tres Pasos Formation at Cerro Divisadero, Chile. Sedimentology, 56(3):737-764. 
Rossi, V. M., Perillo, M. M., Steel, R. J., and Olariu, C. (2017). Quantifying mixed-process variability in shallow-marine depositional systems: What are sedimentary structures really telling us? Journal of Sedimentary Research, 87(10):1060-1074.

Sadler, P. M. (1982). Bed-thickness and grain size of turbidites. Sedimentology, 29(1):37-51.

Selley, R. (1985). Ancient sedimentary environments and their subsurface diagnosis. Chapman and Hall, New York, NY.

Smith, W. (1815). A Memoir to the Map and Delineation of the Strata of England and Wales with Part of Scotland. John Cary.

Spencer, D. W. (1963). The interpretation of grain size distribution curves of clastic sediments. Journal of Sedimentary Research, 33(1):180-190.

Sumner, E. J., Talling, P. J., Amy, L. A., Wynn, R. B., Stevenson, C. J., and Frenz, M. (2012). Facies architecture of individual basin-plain turbidites: Comparison with existing models and implications for flow processes. Sedimentology, 59(6):1850-1887.

Sylvester, Z. (2007). Turbidite bed thickness distributions: Methods and pitfalls of analysis and modelling. Sedimentology, 54(4):847-870.

Sylvester, Z. and Lowe, D. R. (2004). Textural trends in turbidites and slurry beds from the Oligocene flysch of the East Carpathians, Romania. Sedimentology, 51(5):945-972.

Syvitski, J. P. et al. (1991). Principles, methods, and application of particle size analysis. Cambridge University Press.

Talling, P. J. (2001). On the frequency distribution of turbidite thickness. Sedimentology, 48(6):1297-1329.

Thompson, J. A., Burbank, D. W., Li, T., Chen, J., and Bookhagen, B. (2015) Late Miocene northward propagation of the northeast Pamir thrust system, northwest China. Tectonics, 34(3):510-534.

Tőkés, L. and Patacci, M. (2018). Quantifying tabularity of turbidite beds and its relationship to the inferred degree of basin confinement. Marine and Petroleum Geology, 97:659-671.

Udden, J. A. (1914). Mechanical composition of clastic sediments. Bulletin of the Geological Society of America, 25(1):655-744.

Van Wagoner, J., Posamentier, H., Mitchum, R., Vail, P., Sarg, J., Loutit, T., and Hardenbol, J. (1988). An overview of the fundamentals of sequence stratigraphy and key definitions.

Vento, N. F. R. (2020). Hypothesis-Based Machine Learning for Deep-Water Channel Systems. PhD thesis, Colorado State University.

Visher, G. S. (1969). Grain size distributions and depositional processes. Journal of Sedimentary Research, 39(3).

Walker, R. G. (1965). The origin and significance of the internal sedimentary structures of turbidites. In Proceedings of the Yorkshire Geological Society, volume 35, pages 1-32. Geological Society of London.

Walker, R. G. (1978). Deep-water sandstone facies and ancient submarine fans: models for exploration for stratigraphic traps. AAPG Bulletin, 62(6):932-966.

Wentworth, C. K. (1922). A scale of grade and class terms for clastic sediments. The Journal of Geology, 30(5):377-392.

Williams, S. J., Arsenault, M. A., Buczkowski, B. J., Reid, J. A., Flocks, J., Kulp, M. A., Penland, S., and Jenkins, C. J. (2006). Surficial sediment character of the Louisiana offshore Continental Shelf region: a GIS Compilation. Technical report, US Geological Survey Open-File Report 2006-1195.

Willis, B. J. and White, C. D. (2000). Quantitative outcrop data for flow simulation. Journal of Sedimentary Research, 70(4):788-802.

Wouters, S., Da Silva, A.-C., Crucifix, M., Sinnesael, M., Zivanovic, M., Boulvain, F., and Devleeschouwer, X. (2019). Litholog generation with the StratigrapheR package and signal decomposition for cyclostratigraphic purposes. In Geophysical Research Abstracts, volume 21, http:/ / hdl.handle.net/2268/234402.

Zervas, D., Nichols, G. J., Hall, R., Smyth, H. R., Lüthje, C., and Murtagh, F. (2009). SedLog: A shareware program for drawing graphic logs and $\log$ data manipulation. Computers \& Geosciences, 35(10):2151-2159. 